\title{
CrimRxiv
}

\section{Review 2 of "Child Sex Abusers in Protestant Christian Churches: An Offender Typology"}

Kendra Bowen

Published on: Jan 13, 2022

License: Creative Commons Attribution 4.0 International License (CC-BY 4.0). 
Vote: Publish pending minor changes

[For votes to count, referees must reasonably explain why they voted as they did. Thus, please explain your vote. If you voted to publish pending minor changes, specify each change, why it is needed, and, possibly, how it should/could be done.]

The author is possibly missing some research on the topic. In addition, small changes/details are needed throughout the paper.

[Please put additional info below, as/if you see fit:]

I commend you on researching this interesting topic. My comments are below. I believe that if you follow some or all of these suggestions that it will enhance your manuscript for publication.

Add Research on the topic: Terry has conducted a lot of research on the Catholic Church. I know it is a different religious institution, but I think your literature review would benefit greatly if you included more of her research. Also check out:

Frick, B., Moser, K., \& Simmons, R. (2021). Spillover effects of scandals on exits from the Catholic and Protestant Churches in Germany. Journal of Scientific Study of Religion, 60(3), 482-497.

- I know it is in Germany but resources and general info. may be helpful. There are actually more than a couple of peer reviewed articles about Protestant Churches in Germany. Maybe you could add a section about it being studied more there?

https://southernmarylandchronicle.com/2021/04/08/how-protestant-churches-hidsexual-abuse/

https://www.christianitytoday.com/news/2019/may/lifeway-protestant-abuse-surveyyoung-christians-leave-chur.html

Introduction Section:

- $3^{\text {rd }}$ paragraph that starts with "Some estimates exist on the total instances of sexual abuse within these settings." Since this is a new paragraph, please state what "these" mean.

- Same paragraph: Please concisely detail the Downen, Olsen, \& Tedesco (2019) studies findings. 
Age \& Sexual Victimization Section:

- The last sentence of the paragraph (with Denney et al., 2018) can be incorporated with the sentence before it.

Methods Section:

- Define local news (1 ${ }^{\text {st }}$ paragraph)

- What 3 individual websites (1 ${ }^{\text {st }}$ paragraph)

- How were the 326 chosen?

Findings Section:

- Some of the descriptives add up to more than 326 cases that you listed in the methods. For example, one says $n=363$.

The Serial Offender Section:

- The sentence "In contrast, serial offenders were chosen if they had more than one known victim at the time of the arrest." So, anything over 1 is legitimately serial (like only 2). Just wanted to make sure this is right.

- Are the numbers in the paragraph about the $3^{\text {rd }}$ reason right? They seem off.

- Serial represent half of the offender types with only 11 ?

Sorry if I am missing something with this section.

Implications

- Relate to what policies have been instituted to by the institution. Are there other religious institutions who have implemented practices that would be good for the Protestant Churches to implement?

Overall Paper: minor grammatical problems. A thorough reread will catch them (for example, first paragraph of Introduction, a "the" should be "these". Additionally, some of the paragraphs can use transitions to improve the overall paper. Lastly, several sources are dated when used to cite general research. See if you can find some updated research. 